\title{
Cantos e cantares em Contos negreiros, de Marcelino Freire
}

Francesco Jordani Rodrigues de Lima

Universidade Federal do Rio de Janeiro

RESUMO: ANÁLISE CRÍTICA DO LIVRO DE CONTOS DE MARCELINO FREIRE, CONTOS NEGREIROS (2005). A FORÇA LITERÁRIA DO TEXTO A PARTIR DO DUALISMO ESTRUTURAL E DA AMBIGÜIDADE CONSTITUTIVA DA OBRA. A VIOLÊNCIA INTERNA DO DISCURSO MARGINAL. A COMPLEXIDADE ESTRUTURAL DA SOCIEDADE BRASILEIRA E A QUESTÃO DA CONSCIÊNCIA NEGRA. BREVE INSERÇÃO DO TRABALHO DE MARCELINO FREIRE NO PAINEL LITERÁRIO BRASILEIRO.

ABSTRACT: CRITICAL ANALYSIS OF THE BOOK OF STORIES OF MARCELINO FREIRE, CONTOS NEGREIROS (2005). THE LITERATURE STRENGTH OF THE TEXT FROM THE STRUCTURAL DUALISM AND THE CONSTITUTIVE AMBIGUITY OF THE BOOK. THE INTERNAL VIOLENCE OF THE MARGINAL SPEECH. THE STRUCTURAL COMPLEXITY OF THE BRAZILIAN SOCIETY AND THE QUESTION OF THE BLACK AWARENESS. BASIC INSERTION OF THE WORK OF MARCELINO FREIRE IN THE LITERARY BRAZILIAN PANEL.

PALAVRAS-CHAVE: LITERATURA BRASILEIRA - MARCELINO FREIRE - CULTURA NEGRA - CRÍTICA SOCIAL E ORALIDADE KEY-WORDS: BRAZILIAN LITERATURE - MARCELINO FREIRE - BLACK CULTURE - SOCIAL CRITICISM AND ORALITY 


\section{(Des)encanto:}

Habitada por gente tão simples e tão pobre

Que só tem o sol que a todos cobre

Como podes, Mangueira, cantar?

Cartola, "Sala de recepção"

possível exibir e camuflar, cantar e silenciar, cuidar e açoitar ao mesmo tempo? Sobre quantas contradições permanece a problemática do negro e dos trabalhadores pobres na história do Brasil? Como pudemos reservar aos miseráveis somente os cantos da injustiça social, os becos das favelas, os quartos dos fundos, as marquises, as bocas-de-fumo, os cárceres e os barracos, enquanto seus cantos pouco ecoavam, abafados pela mordaça da violência, pelo tapa do preconceito, pela inocuidade da imagem comercializada, estereotipada e massificada que tanto nos divertiu à custa da fatalidade dos bons selvagens, das pretas velhas, dos malandros e meretrizes, dos sambistas e mulatas, das funkeiras e MCs - todos a requebrar para nós seus corpos flagelados?

Não resta dúvida de que na memória brasileira a figura do negro geralmente é mais corpo que mente, mais gingado que palavra, mais silêncio que expressão. É, contudo, com franca oposição à brutalidade desse cenário que a marginália ${ }^{1}$ canta e vive seus mais profundos desencantos em Contos negreiros, de Marcelino Freire. Desafia e desmistifica o estigma da negritude passiva, pacífica e naturalmente feliz. Apaga da própria imagem o verniz exótico-romântico e a maquiagem da compensação social, a fim de deflagrar a urgência do grito e do gesto detidos. "Hein seu branco safado? Ninguém aqui é escravo de ninguém" (FREIRE, 2005: 20), entoa o narrador logo no primeiro dos dezesseis cantos-contos, como se esbravejasse a todos que por falta de contundência, dali em diante, não padecerá sua voz.

Na obra de Marcelino Freire, a firmeza do posicionamento não denota somente um engajamento político ou a reafirmação da luta das populações pauperizadas. Embora estes sejam aspectos relevantes, o conjunto de contos, cada qual cantado de maneira singular, ressalta, sobretudo, o discurso crítico e pungente dos narradores e personagens acerca da própria situação. Ao

1 Título do conjunto de crônicas de Lima Barreto (1881-1922) publicadas postumamente, em 1953. 
escavar as entranhas da realidade dos marginalizados, pela voz dos próprios e não pela onisciência ditatorial do discurso dominante, o que emerge é o sofrimento desprovido de autocomplacência e, sobretudo, a avaliação clara e impactante da posição do negro e dos pobres na construção da sociedade brasileira mercantilista e capitalista. Carlos Nelson Coutinho observa em ensaio como as camadas populares "são freqüentemente decapitadas e lutam com grande dificuldade para dar uma figura sistemática à sua autoconsciência ideológica" (COUTINHO apud RESENDE, 1983: 74).

A leitura de Contos negreiros é, portanto, muito mais abrangente do que a requerida habitualmente pelo romance brasileiro (sobretudo durante o Romantismo, exceto em raríssimos autores), no qual a classe pobre, principalmente os negros, não ultrapassa a posição de mero componente da verossimilhança do painel social, ou de um adorno "com a única intenção de criar um pouco de colorido" (RABASSA, 1965: 95). A estrutura ambivalente da obra de Marcelino Freire responde de maneira impressionante tanto pelo destaque dado às raízes da cultura negra oralizada, que privilegia a memória coletiva enquanto manancial cultural, quanto pela mistura de etnias, costumes e línguas na qual se fundamenta o movimentado organismo social brasileiro. Ao se ancorar na dinâmica ambigüidade do canto/conto (isto é, da canção e do relato, do lirismo e do documento e, conseqüentemente, da ficção e da história), o livro sintetiza em seu núcleo de paradoxos complementares o complexo engendramento do país.

Como exemplo da estrutura dual do livro, citemos mais um trecho do canto I, "Trabalhadores do Brasil", que evoca a presença de diversos orixás, inclusive o maior de todos, Olorum, acompanhados de figuras negras históricas e do mundo das fábulas, que vão desde Zumbi dos Palmares e Rainha Quelé (apelido da cantora Clementina de Jesus) até cavaleiro Tição, um jovem esquartejado pelo próprio exército ao defender o castelo de Trancoso, em Portugal.

Enquanto Zumbi trabalha cortando cana na zona da mata pernambucana OlorôQuê vende carne de segunda a segunda ninguém vive aqui com a bunda preta pra cima tá me ouvindo bem?

Enquanto a gente dança no bico da garrafinha Odé trabalha de segurança pega ladrão que não respeita quem ganha pão que o Tição amassou honestamente enquanto Obatalá faz o serviço pra muita gente que não levanta um saco de cimento tá me ouvindo bem? (FREIRE, 2005: 19) 
Fica claro que em Contos negreiros o posicionamento crítico não cai no terreno previsível do panfleto moralizante, pois flui no ritmo e na força de cantos multirrítmicos genuínos do povo negro e pobre (canto banto, samba, rap, funk). Os cantares tampouco se apresentam superficiais ou decorativos, porque, além de não serem meros recursos sonoros e estéticos, trazem presos à garganta a tensão do apartheid brasileiro. Na obra, a língua do texto serve à embocadura de quem fala e sente as frustrações de um cotidiano de recusas e espoliações.

Ao lado dos guerreiros orixás, os personagens históricos criam na ficção o terreno propício para, unidos, cantarem sua revolta e chamarem para si a atenção de ouvidos moucos, repletos de desprezo e preconceito. Assim, os conceitos ortodoxos de história documental e tempo cronológico se diluem para dar espaço à genuína pluralidade da cultura negra que não fora devidamente registrada, como boa parte da cultura ocidental européia, mas, sim, lembrada sob a forma de um imenso mosaico de músicas, danças, religiões, tradições, memórias familiares e rituais de comunidades oprimidas pela elite.

Cabe aqui ressaltar um trecho do fundamental Literatura e sociedade, de Antonio Candido. Raros são os instantes de tamanha lucidez na fortuna crítica literária nacional no que tange à "interpretação estética que assimilou a dimensão social como fator de arte" (CANDIDO, 1985: 7).

Esta liberdade, mesmo dentro da orientação documentária, é o quinhão da fantasia, que às vezes precisa modificar a ordem do mundo justamente para tornála mais expressiva; de tal maneira que o sentimento de verdade se constitui no leitor graças a esta traição metódica. Tal paradoxo está no cerne do trabalho literário e garante a sua eficácia como representação do mundo. Achar, pois, que basta aferir a obra com a realidade exterior para entendê-la, é correr o risco de uma perigosa simplificação causal. (CANDIDO, 1985: 14)

Os cantos dos Contos negreiros, de Marcelino Freire, encantam do ponto de vista da imensa qualidade estética e estrutural do objeto artístico, porém, não deixam, paradoxalmente, de deflagrar, no afã do discurso rasgado, o desencanto da massa trabalhadora somente incluída enquanto exército de reserva ou de produção de capital. São essas mulheres e homens esmagados pela contraditória estrutura excludente/includente do capitalismo, os seres do abismo 
e dos cantos sociais, os protagonistas de um bloco que canta o que bem quer e não mais solicita passagem.

\section{Cantos e cantares:}

A carne mais barata do mercado é a carne negra. Seu Jorge, Marcelo Yuka e Ulisses Cappelletti, "A carne"

A indagação acerca da questão social não é recente na literatura brasileira. Se o passado brasileiro do texto verdadeiramente empenhado nos deixou figuras de relevo em escala reduzida, vide os poucos poemas de Gregório de Matos e dos inconfidentes mineiros, passou a criar vulto com as obras de Castro Alves, Cruz e Sousa, Lima Barreto e Jorge de Lima (aos quais são dedicados os Contos negreiros). Foi, contudo, no decorrer do século XX que, definitivamente, inflou-se e pluralizou-se a cena artística engajada. Graciliano Ramos, José Lins do Rego e Jorge Amado, para citar apenas alguns grandes narradores, ao lado dos poetas Drummond, João Cabral de Melo Neto e Ferreira Gullar, de fato, são numerosos os artistas que dirigiram suas preocupações "para o papel e presença do tema literário da desigualdade, da marginalização, da pobreza” (ROSATI, 2003: 9).

Outro grupo importante foi o constituído por autores que se voltaram contra a censura ditatorial nos anos 1960/70, no qual ressaltam os nomes de Rubem Fonseca, Ignácio de Loyola Brandão e Ivan Ângelo. O primeiro, inclusive, destacando-se como referência recorrente quando se trata de prosa urbana. Isso sem citarmos as valiosas produções no âmbito da crônica jornalística, da música, do cinema, do teatro e das artes plásticas, que, indubitavelmente, polinizam o literário.

Importa saber, em vista desse quadro amplo e, ainda assim, demasiadamente incompleto, como se dá a específica inserção da obra de Marcelino Freire na arte brasileira. Desde seu livro de estréia, Angu de sangue (2000), a firmeza e a acidez do discurso narrativo se impõem como características fundamentais. A questão da sobrevivência digna das camadas populares, fixadas sempre sobre o signo do trabalho, dá aos narradores e personagens de Marcelino Freire uma rara feição de autenticidade, pois a miséria social e econômica 
não resulta na miséria moral dos protagonistas. O conto "Muribeca", nome de um antigo lixão na capital pernambucana que passou por uma reforma da prefeitura municipal, é também um canto que ressoa a imensa pobreza do estado social, mas que não deteriora a vontade dos abandonados de viverem de maneira honesta:

Fale, fale. Explique o que é que a gente vai fazer da vida? O que a gente vai fazer da vida? Não pense que é fácil. Nem remédio pra dor de cabeça eu tenho. Como vou me curar quando me der uma dor no estômago, uma coceira, uma caganeira? Vá, me fale, me diga, me aconselhe. Onde vou encontrar tanto remédio bom? [...]

O povo do governo devia pensar três vezes antes de fazer isso com chefe de família. Vai ver que eles tão de olho nessa merda aqui. Nesse terreno. Vai ver que eles perderam alguma coisa. É. Se perderam, a gente acha. A gente cata. A gente encontra. Até bilhete de loteria, lembro, teve gente que achou. Vai ver que é isso, coisa da Caixa Econômica. Vai ver que é isso, descobriram que lixo dá lucro, que pode dar sorte, que é luxo, que lixo tem valor. Por exemplo, onde a gente vai morar, é? Onde a gente vai morar? Aqueles barracos, tudo ali em volta do lixão, quem é que vai levantar? Você, o governador? Não. [...]

Não, eles nunca vão tirar a gente deste lixão. Tenho fé em Deus, com a ajuda de Deus eles nunca vão tirar a gente deste lixo. Eles dizem que sim, que vão. Mas não acredito. Eles nunca vão conseguir tirar a gente deste paraíso. (FREIRE, 2000: 56)

Podemos, portanto, nos valer das palavras de Rosati, no estudo Ficções brasileiras atuais - literatura e realidade, para afirmar que a narrativa de Marcelino Freire se insere

no panorama cultural dos grandes centros, de um tipo de ficção literária marcada por um caráter realista, abordando em tom direto, problemáticas ligadas à injustiça social e à deterioração da vida na grande cidade [...], numa trama urdida com o fio, quase sempre vermelho, da violência. (ROSATI, 2003: 6)

A violência, porém, não surge na tessitura literária de Contos negreiros, tampouco em qualquer outra obra do autor pernambucano, como um elemento 
externo ao ficcional, ou uma matéria-prima colhida tão-somente em virtude do fazer artístico. A violência surge interna ao discurso dos marginalizados, que, ao corroer a superficialidade da realidade alienante na qual vivemos, fragmenta a unidade lógica do cânone e dilacera, também, a nós leitores, como que "violentados" pela força impressionante de um canto catártico, cuspido e inquieto. O título do canto III, "Esquece”, reforça o desprezo comum em relação aos segmentos mais pauperizados da classe trabalhadora:

Violência é o carrão parar em cima do pé da gente e fechar a janela de vidro fumê e a gente nem ter a chance de ver a cara do palhaço de gravata para não perder a hora ele olha o tempo perdido no rolex dourado.

Violência é a gente naquele sol e o cara dentro do ar condicionado uma duas três horas quatro esperando a melhor oportunidade de a gente enfiar o revólver na cara do cara plac.

$[\ldots]$

Violência é acabarem com nossa esperança de chegar lá no barraco e beijar as crianças e ligar a televisão e ver aquela mesma discussão ladrão que rouba ladrão a aprovação do mínimo ficou para a próxima semana.

$[\ldots]$

Violência é a gente receber tapa na cara e na bunda quando socam a gente naquela cela imunda cheia de gente e mais gente e mais gente pensando como seria bom ter um carrão do ano e aquele relógio rolex mas isso fica para uma outra hora.

Esquece. (FREIRE, 2005: 31-33)

Ronaldo Lima Lins afirma que "a catarse representaria, portanto, um elemento de violência que a arte sempre utilizou em seu próprio benefício como transmissora, numa dose controlável, de uma outra violência, a da vida" (LINS, 1990: 38). O canto, grito há muito contido, só é genuíno na ficção de Marcelino Freire justamente porque não é notado, nem proferido, enquanto matéria subserviente ao plano literário. Tanto que em Contos negreiros alguns cantos se assemelham a verdadeiros desabafos dos homens que habitam o que nesse texto denominamos "cantos sociais" - territórios marcados pelo medo da solidão, do preconceito e do abandono. Isso ocorre no canto XIV, "Curso superior", de estrutura idêntica à do anteriormente citado, no qual a repetição do início dos parágrafos confirma a clara referência à rima musical: 
O meu medo é entrar na faculdade e tirar zero eu que nunca fui bom de matemática fraco no inglês eu que nunca gostei de química geografia e português o que é que eu faço agora hein mãe não sei.

O meu medo é o preconceito e o professor ficar me perguntando o tempo inteiro por que eu não passei por que eu não passei por que eu fiquei olhando aquela loira gostosa o que é que eu faço se ela me der bola hein mãe não sei. $[\ldots]$

O meu medo é do pai da loira gostosa e da mãe da loira gostosa e do irmão da loira gostosa e do irmão da loira gostosa no dia em que a loira gostosa me apresentar para a família como o homem da sua vida será que é verdade será que isso é felicidade hein mãe não sei.

$[\ldots]$

O meu medo é que mesmo com diploma debaixo do braço andando por aí desiludido e desempregado o policial me olhe de cara feia e eu acabe fazendo uma burrice sei lá uma besteira será que eu vou ter direito a uma cela especial hein mãe não sei. (FREIRE, 2005: 97-98)

Note-se que, em ambos os contos, o local em que culmina o drama dos cantores (narradores-personagens) é a cela de prisão. Da senzala da escravidão ao cárcere contemporâneo, a imagem fixa dos limites impostos socialmente às camadas periféricas é fruto preciso de uma visão crítica profunda acerca da história da formação brasileira. Os "seres dos cantos" não são apenas os negros presumíveis no título da obra. Enfileiram-se em Contos negreiros os desempregados, os homossexuais, as crianças sonhadoras ou vítimas do turismo sexual, os índios, as prostitutas, as donas-de-casa descrentes, dentre outras vozes que compõem o hino seco e desalentado dos "esfarrapados do mundo"2.

Observemos como o grau de afirmação da ambigüidade do vocábulo "canto" aumenta no decorrer dos cantos-contos da obra:

Cachorro a gente enterra em qualquer canto.

Enterra aí, Zé. E pronto. (FREIRE, 2005: 69)

2 Assim o pedagogo pernambucano Paulo Freire denominava os socialmente oprimidos. 
Capim sabe ler? Escrever? Já viu cachorro letrado, científico? Já viu juízo de valor? Em quê? Não quero aprender, dispenso.

Deixa pra gente que é moço. Gente que tem ainda vontade de doutorar. De falar bonito. De salvar vida de pobre. O pobre só precisa ser pobre. E mais nada precisa. Deixa eu aqui, no meu canto. Na boca do fogão é que fico. Tô bem. Já viu fogo ir atrás de sílaba? (FREIRE, 2005: 79)

Dizem que lá tem muita criança na rua.

Nua.

É comum, por todo canto. Dizem que tem menina abandonada em Rondônia, Roraima. No Ceará, em Pernambuco. Vendidas no coração de Rio Branco. (FREIRE, 2005: 108)

Logo nas primeiras linhas de Literatura e sociedade, Antonio Candido afirma: "Nada mais importante para chamar a atenção sobre uma verdade do que exagerá-la" (CANDIDO, 1985: 3). Antes, ainda, pondera o teórico, atento para o movimento contrário da crítica que reagiria contra o absurdo do feito. Assim, Candido reflete acerca da análise que procurou fundamentar o valor da obra de arte na qualidade da reprodução do elemento externo, a realidade social. Não esquece, também, da outra face que compreendeu a arte como produção independente do painel construído historicamente pelos homens.

Para Candido, norte teórico deste trabalho, a realidade social nunca será externa numa obra literária, pois, quando é transposto para a estrutura do livro, o elemento dito externo passa a importar "não como causa, nem como significado, mas como elemento que desempenha um certo papel na constituição da estrutura, tornando-se, portanto, interno" (CANDIDO, 1985: 4).

Embora bem mais complexa do que a previsão de qualquer análise literária, a obra Contos negreiros, de Marcelino Freire, traz em sua configuração justamente a complexidade estrutural e a ambigüidade formativa da sociedade brasileira. Uma vastidão territorial para os grandes latifúndios e os becos da periferia para os barracos, os cortiços, as ocas, as casas de massapê. Um país soerguido sobre a estrutura injusta e paradoxal do capitalismo excludente na divisão do lucro produzido e includente na convocação dos milhões de desempregados, desvalidos, subjugados.

Na obra de Marcelino Freire, tudo é interno, pois ainda há muitíssimo a ser cantado e descarnado. O grande exagero, portanto, não é o que emerge da 
contraditória "realidade ficcional" dos Contos negreiros, muito menos o colhido e reproduzido da realidade social brasileira, mas, sobretudo, o grande exagero foi e é o silêncio que mantemos passivamente sobre esse assunto cada vez que lemos os jornais, folheamos uma revista ou ligamos a TV. Esse verdadeiramente "é o fim" (FREIRE, 2005: 101) dos personagens e das pessoas que giram caoticamente em torno desse belo livro. Esse é nosso fim.

Resistindo à opressão

Nossos negros dentes

Suportando a bumilhação

O olho cresceu, primeiro chegon

O couro comeu, o pau rançou

Mas o negro é aroeira, envergou mas não quebrou.

Nei Lopes, "Nosso nome, resistência"

\section{Referências Bibliográficas}

CANDIDO, Antonio. Literatura e sociedade - estudos de teoria e história literária. São Paulo: Nacional, 1985.

FIORIN, José Luiz. Linguagem e ideologia. 6. ed. São Paulo: Ática, 1998.FREIRE, Marcelino. Contos negreiros. Rio de Janeiro: Record, 2005.

KONDER, Leandro. A questão da ideologia. São Paulo: Companhia das Letras, 2002.

LINS, Ronaldo Lima. Violência e literatura. Rio de Janeiro: Tempo Brasileiro, 1990.

RABASSA, Gregory. O negro na fiçãa brasileira: meio século de história literária. Rio de Janeiro: Tempo Brasileiro, 1965.

RESENDE, Beatriz. Lima Barreto - a opção pela Marginalia. In: SCHWARZ, Roberto (org.). Os pobres na literatura brasileira. São Paulo: Brasiliense, 1983.

ROSATI, Luiz Alfredo Reis. Ficções brasileiras atuais - literatura e realidade. 2003. 95 fl. Dissertação de Mestrado em Literatura Brasileira, Universidade Federal do Rio de Janeiro, Rio de Janeiro, 2003. 